\title{
In vitro antimicrobial susceptibility patterns of Propionibacterium acnes isolated from patients with acne vulgaris
}

\author{
Indu Biswal ${ }^{1}$, Rajni Gaind ${ }^{1}$, Neeraj Kumar ${ }^{2}$, Srujana Mohanty ${ }^{1}$, Vikas Manchanda ${ }^{3}$, Niti Khunger ${ }^{2}$, Ramesh \\ $\mathrm{V}^{2}$, Manorama Deb ${ }^{1}$ \\ ${ }^{1}$ Department of Microbiology, Vardhman Mahavir Medical College and Safdarjang Hospital, New Delhi, India \\ 2 Department of Skin and Venereal Diseases, Vardhman Mahavir Medical College and Safdarjang Hospital, New \\ Delhi, India \\ ${ }^{3}$ Department of Microbiology, Maulana Azad Medical College, India
}

\begin{abstract}
Introduction: Propionibacterium acnes has been implicated in the development of acne vulgaris. Rampant use of topical and systemic antibiotics for acne vulgaris has led to resistance due to selective pressure. This study aimed to determine antibiotic resistance of $P$. acnes. Methodology: A total of 102 samples were collected from acne lesions and cultured onto sheep's blood agar and brain-heart infusion agar supplemented with $5 \mathrm{~g} / \mathrm{L}$ glucose and $2 \mathrm{mg} / \mathrm{L}$ furazolidone) (BHIg) under aerobic and anaerobic conditions. Species identification was done by conventional methods and the VITEK2 Compact system. The isolates were tested for penicillin, erythromycin, clindamycin, ciprofloxacin, nadifloxacin, and tetracycline by E-test, and minimum inhibitory concentration (MIC) of minocycline was determined by agar dilution on BHIg. MIC results were interpreted as per EUCAST (European Committee on Antimicrobial Susceptibility Testing) and CLSI (Clinical Laboratory Standards Institute) guidelines.

Results: P. acnes was the most common anaerobe (66\%) isolated. Resistance rates using EUCAST and CLSI breakpoints were $10.6 \%$ and $6.1 \%, 7.6 \%$ and $0 \%, 7.8 \%$ and $0 \%$ for erythromycin, clindamycin, and minocycline, respectively. Tetracycline resistance was observed in $9.2 \%$ isolates irrespective of the interpretative criteria used. $\mathrm{MIC}_{50}$ and $\mathrm{MIC}_{90}$ values for nadifloxacin $(0.25$ and $1 \mu \mathrm{g} / \mathrm{mL})$ were found to be twofold lower than those for ciprofloxacin $(0.5$ and $1 \mu \mathrm{g} / \mathrm{mL})$. Similarly, $\mathrm{MIC}_{50}$ and MIC90 values for minocycline $(0.125 \mathrm{and} 0.5 \mu \mathrm{g} / \mathrm{mL}) \mathrm{were}$ also two- to threefold lower than those for tetracycline $(0.38$ and $1 \mu \mathrm{g} / \mathrm{mL})$.

Conclusions: To the best of our knowledge, this is the first study focusing on P. acnes resistance from India.
\end{abstract}

Key words: Propionibacterium acnes; acne vulgaris; EUCAST; CLSI.

J Infect Dev Ctries 2016; 10(10):1140-1145. doi:10.3855/jidc.6862

(Received 12 March 2015 - Accepted 13 June 2015)

Copyright (C) 2016 Biswal et al. This is an open-access article distributed under the Creative Commons Attribution License, which permits unrestricted use, distribution, and reproduction in any medium, provided the original work is properly cited.

\section{Introduction}

Acne vulgaris is a chronic inflammatory disorder of pilosebaceous follicles that affects more than $85 \%$ of adolescents and young adults [1]. It is characterized by a pleomorphic eruption of comedones, erythematous papules, pustules, and sometimes nodules, frequently followed by scarring [2]. Acne is not an infectious disease, but organisms residing on the surface of skin and pilosebaceous ducts may trigger infection. These organisms include Propionibacterium acnes, Staphylococcus epidermidis, and Staphylococcus aureus. Pathogenesis of acne is a complex interplay of inflammation, hyperkeratinisation of the sebaceous duct, high sensitivity to circulating androgens, and bacterial colonization [2]. Topical antibiotics such as erythromycin, clindamycin, and tetracycline are routinely used for long-term treatment of acne vulgaris, which exerts considerable selective pressure for the development of drug resistance [3]. This study was undertaken to examine the bacteriological profile of acne vulgaris and to ascertain its antimicrobial resistance patterns.

\section{Methodology}

A cross-sectional study was undertaken in the outpatient department of dermatology, Safdarjang Hospital, over a period of two years between 2010 and 2012. A total of 102 patients with acne vulgaris were included after informed consent was obtained. The study was approved by ethical committee of Safdarjang hospital (reference 52-11-EC [17/17]). Detailed history and clinical examination was carried out with reference to Pillsbury grading [4]. 


\section{Skin sampling}

Samples were collected from acne lesions (38 comedones, 18 papules, and 44 pustules) by aseptic techniques using a comedone extractor. In the case of closed comedones (whiteheads), papules, and pustules, the lesion was punctured with a sterile hypodermic needle $(25 \times 35 \mathrm{~mm})$ using aseptic precautions. All specimens were subjected to aerobic and anaerobic culture.

\section{Bacteriological study}

The specimens were inoculated onto 5\% sheep's blood agar, MacConkey agar, and brain-heart infusion agar (HiMedia, Mumbai, India) supplemented with 5 $\mathrm{g} / \mathrm{L}$ glucose and $2 \mathrm{mg} / \mathrm{L}$ furazolidone. Plates were incubated at $37^{\circ} \mathrm{C}$ under both aerobic and anaerobic conditions for 2-7 days and examined for growth. Anaerobic culture was performed using the Gaspak system (HiMedia Labs., Mumbai, India).

\section{Identification}

Aerobic and anaerobic bacteria were identified by Gram stain, colony morphology, and standard biochemical tests [5]. P. acnes strains were presumptively identified as Gram-positive bacilli grown anaerobically with positive indole, catalase, and nitrate reduction tests. Final identification was confirmed by the automated VITEK2 Compact (Biomerieux, Marcy l'Etoile, France) system.

Table 1. Clinical and bacteriological profile of patients.

\begin{tabular}{|c|c|}
\hline Profile & $\begin{array}{c}\text { No. of patients (\%) } \\
n=102\end{array}$ \\
\hline \multicolumn{2}{|l|}{ Age at inclusion } \\
\hline Mean/median & $18.74 / 19$ \\
\hline $\operatorname{Min} / \max$ & $11 / 29$ \\
\hline \multicolumn{2}{|l|}{ Gender } \\
\hline Male & $63(63 \%)$ \\
\hline Female & $37(37 \%)$ \\
\hline \multicolumn{2}{|l|}{ Grades of acne } \\
\hline Grade 1 & $32(32 \%)$ \\
\hline Grade 2 & $26(26 \%)$ \\
\hline Grade 3 & $30(30 \%)$ \\
\hline Grade 4 & $12(12 \%)$ \\
\hline \multicolumn{2}{|l|}{ Family history of acne } \\
\hline No & $56(56 \%)$ \\
\hline Yes & $44(44 \%)$ \\
\hline \multicolumn{2}{|l|}{ Type of lesion sampled } \\
\hline Comedones & $38(38 \%)$ \\
\hline Pustule & $44(44 \%)$ \\
\hline Papule & $18(18 \%)$ \\
\hline \multicolumn{2}{|l|}{ Bacteriological profile } \\
\hline \multicolumn{2}{|l|}{ Aerobes } \\
\hline Staphylococcus aureus & $65(65 \%)$ \\
\hline Staphylococcus epidermidis & $5(5 \%)$ \\
\hline Klebsiella pneumoniae & $4(4 \%)$ \\
\hline Escherichia coli & $2(2 \%)$ \\
\hline Citrobacter freundii & $1(1 \%)$ \\
\hline Enterobacter aerogenes & $1(1 \%)$ \\
\hline \multicolumn{2}{|l|}{ Anaerobes } \\
\hline Propionibacterium acnes & $66(66 \%)$ \\
\hline Propionibacterium granulosum & $2(2 \%)$ \\
\hline Propionibacterium propionicus & $1(1 \%)$ \\
\hline Clostridium sp. & $1(1 \%)$ \\
\hline \multicolumn{2}{|l|}{ Mixed growth } \\
\hline Propionibacterium acnes + Staphylococcus aureus & $39(39 \%)$ \\
\hline Propionibacterium acnes + Staphylococcus epidermidis & $3(3 \%)$ \\
\hline Clostridium sp. + Enterococcus sp. & $1(1 \%)$ \\
\hline Klebsiella pneumonia + Staphylococcus aureus & $2(2 \%)$ \\
\hline Escherichia coli + Cirobacter $\mathrm{sp}$ & $1(1 \%)$ \\
\hline
\end{tabular}




\section{Antibiotic susceptibility}

Antibiotic susceptibility of aerobic isolates was performed on Mueller-Hinton agar (Oxoid Ltd., Basingstoke, England) per Clinical and Laboratory Standards Institute (CLSI) 2011 guidelines [6]. For $P$. acnes, minimum inhibitory concentration (MIC) for erythromycin, clindamycin, ciprofloxacin, and tetracycline were determined by the E-test (AB Biodisk, Solna, Sweden). MICs of minocycline and nadifloxacin (Cipla Industries, Mumbai, India) were determined by agar dilution on BHIg using spot inoculation. Inocula were prepared to a $0.5 \mathrm{MacF}$ arland standard from a 48 hour growth on anaerobic blood agar. MIC results were interpreted per European Committee on Antimicrobial Susceptibility Testing EUCAST [7] and CLSI guidelines [6].

\section{Results}

The demographic and clinical details of acne patients are shown in Table 1. All the patients were between 11 and 29 years of age, with a mean age of 18.7 years. The majority of patients were between 18 and 19 years of age $(27 \%)$, with a predominance of males $(63 \%)$. The patients were also categorized according to Pillsbury grading [4]. Thirty-two percent of the patients belonged to grade 1 , while $26 \%, 30 \%$, and $12 \%$ belonged to grades 2, 3, and 4, respectively. Forty-four percent of patients had a family history of acne, and $14 \%$ had history of previous anti-acne treatment.

The bacteriological profiles of the acne patients are shown in Table 1. Of 102 samples processed, 78\% samples showed aerobic growth and 70\% showed anaerobic growth. S. aureus $(65 ; 65 \%)$ was the predominant aerobe, followed by $S$. epidermidis (5; 5\%) and Klebsiella pneumoniae (4; 4\%). Among the anaerobes, Propionibacterium species were isolated in 69 samples, with $P$. acnes as the predominant species (66; 66\%); Clostridium sp. was isolated from one patient.

\section{Antibiotic susceptibility}

Among $65 \mathrm{~S}$. aureus strains isolated, highest resistance was seen with penicillin $(45 ; 70.2 \%)$, followed by erythromycin $(38 ; 59 \%)$, clindamycin $(25$; $39.7 \%)$, gentamicin $(20 ; 30.3 \%)$, tetracycline $(38$; $25 \%)$, ciprofloxacin $(11 ; 17.9 \%)$, and oxacillin $(13 \%$; $20.4 \%)$. P. acnes also showed resistance to penicillin $(4 ; 6.7 \%)$, erythromycin $(7 ; 10.6 \%)$, clindamycin $(4$; $6.1 \%)$, tetracycline $(6 ; 9.2 \%)$, and ciprofloxacin $(2$; $3 \%)$. No resistance was observed to minocycline $(0$; $0 \%$ ).

Table 2. Clinical breakpoints of P. acnes using EUCAST (2003) and CLSI (2007) guidelines.

\begin{tabular}{ccc}
\hline Antimicrobial & EUCAST clinical breakpoint & CLSI clinical breakpoint \\
\hline Penicillin & $>0.5 \mu \mathrm{g} / \mathrm{mL}$ & $\geq 2 \mu \mathrm{g} / \mathrm{mL}$ \\
Clindamycin & $\geq 0.25 \mu \mathrm{g} / \mathrm{mL}$ & $\geq 8 \mu \mathrm{g} / \mathrm{mL}$ \\
Erythromycin & $\geq 0.5 \mu \mathrm{g} / \mathrm{mL}$ & $\geq 2 \mu \mathrm{g} / \mathrm{mL}$ \\
Tetracycline & $\geq 2 \mu \mathrm{g} / \mathrm{mL}$ & $\geq 16 \mu \mathrm{g} / \mathrm{mL}$ \\
Minocycline & $\mathrm{ND}$ & $\geq 16 \mathrm{mcg} / \mathrm{mL}$ \\
Nadifloxacin & $\mathrm{ND}$ & $\mathrm{ND}$ \\
Ciprofloxacin & $\mathrm{ND}$ & $\geq 8 \mathrm{mcg} / \mathrm{mL}$ \\
\hline
\end{tabular}

EUCAST: European Committee on Antimicrobial Susceptibility Testing; CLSI: Clinical and Laboratory Standards Institute; ND: not defined.

Table 3. Minimum inhibitory concentrations (MICs) of antibiotics against 66 P. acnes isolates.

\begin{tabular}{|c|c|c|c|c|c|c|c|c|c|c|c|c|c|c|c|c|c|c|c|c|c|}
\hline $\begin{array}{c}\text { Antimicrobia } \\
\text { I }\end{array}$ & $\begin{array}{c}\leq \\
0.0 \\
3\end{array}$ & $\begin{array}{l}0.0 \\
47\end{array}$ & $\begin{array}{c}0.0 \\
6\end{array}$ & $\begin{array}{l}0.1 \\
25\end{array}$ & $\begin{array}{c}0.2 \\
5\end{array}$ & $\begin{array}{c}0.3 \\
8\end{array}$ & 0.5 & 1 & 2 & 4 & 8 & 16 & 32 & 64 & 128 & $\underset{256}{\geq}$ & 512 & $\begin{array}{l}\mathrm{MI} \\
\mathrm{C}_{50} \\
\end{array}$ & MIC $_{90}$ & $\begin{array}{c}\text { EUCAST } \\
(\% \mathrm{R})\end{array}$ & $\begin{array}{c}\text { CLSI } \\
(\% \text { R) }\end{array}$ \\
\hline Penicillin & 38 & 0 & 24 & 0 & 0 & 0 & 0 & 0 & 0 & 0 & 0 & 0 & 4 & 0 & 0 & 0 & 0 & $\begin{array}{c}0.0 \\
3\end{array}$ & 0.06 & ND & $4(6.1 \%)$ \\
\hline Clindamycin & 0 & 28 & 4 & 27 & 2 & 0 & 2 & 2 & 0 & 1 & 0 & 0 & 0 & 0 & 0 & 0 & 0 & $\begin{array}{l}0.1 \\
25\end{array}$ & 0.25 & $7(10.6 \%)$ & 0 \\
\hline Erythromycin & 30 & 0 & 28 & 3 & 0 & 0 & 1 & 0 & 0 & 0 & 0 & 0 & 0 & 0 & 0 & 0 & 4 & $\begin{array}{c}0.0 \\
6\end{array}$ & 0.25 & $5(7.6 \%)$ & $4(6.1 \%)$ \\
\hline Tetracycline & 0 & 0 & 2 & 11 & 17 & 25 & 3 & 2 & 0 & 0 & 0 & 0 & 5 & 1 & 0 & 0 & 0 & $\begin{array}{c}0.3 \\
8\end{array}$ & 1.0 & $6(9.2 \%)$ & $6(9.2 \%)$ \\
\hline Minocycline & 0 & 0 & 29 & 15 & 11 & 0 & 6 & 0 & 1 & 4 & 0 & 0 & 0 & 0 & 0 & 0 & 0 & $\begin{array}{l}0.1 \\
25\end{array}$ & 0.5 & ND & 0 \\
\hline Ciprofloxacin & 0 & 0 & 4 & 10 & 11 & 17 & 11 & 5 & 4 & 2 & 0 & 0 & 0 & 2 & 0 & 0 & 0 & 0.5 & 2.0 & ND & $2(3.0 \%)$ \\
\hline Nadifloxacin & 0 & 0 & 16 & 17 & 19 & - & 10 & 3 & 1 & 0 & 0 & 0 & 0 & 0 & 0 & 0 & 0 & $\begin{array}{c}0.2 \\
5\end{array}$ & 1.0 & ND & ND \\
\hline
\end{tabular}

EUCAST: European Committee on Antimicrobial Susceptibility Testing; CLSI: Clinical and Laboratory Standards Institute; R: resistant; ND: not defined. 
The clinical breakpoints for $P$. acnes proposed by CLSI and EUCAST are shown in Table 2. Clinical breakpoints have not been proposed for minocycline and ciprofloxacin by EUCAST. No breakpoint values are available for nadifloxacin in either EUCAST or CLSI. $\mathrm{MIC}_{50}, \mathrm{MIC}_{90}$, and $\mathrm{MIC}$ range of all the antibiotics are shown in Table 3. All the antibiotics showed bimodal distribution of resistance against $P$. acnes.

The penicillins showed strong activity against $P$. acnes (MIC range: $0.03-32 \mu \mathrm{g} / \mathrm{mL}$ ), and the majority of the isolates $(38 / 66 ; 58 \%)$ had MICs lower than the lowest antibiotic concentration on the E-test strip. Based on EUCAST guidelines, only $6.7 \%$ of $P$. acnes strains were resistant to penicillin. Topical antibiotics such as clindamycin and erythromycin were active against the majority of $P$. acnes strains, and resistance was observed in $10.6 \%$ and $7.6 \%$ (EUCAST), and $0 \%$ and $6.1 \%$ (CLSI) of strains, respectively. No inducible clindamycin resistance was observed in these strains.

The majority of the strains were sensitive to ciprofloxacin ( $\mathrm{MIC}<0.5 \mu \mathrm{g} / \mathrm{mL}$ ). Low-level resistance was seen in 11 strains (MIC: $0.5-4 \mu \mathrm{g} / \mathrm{mL}$ ), and two strains $(3.0 \%)$ showed high-level resistance (MIC $>8$ $\mu \mathrm{g} / \mathrm{mL}$ ) (CLSI). Nadifloxacin, a topical fluoroquinolone, demonstrated high activity against $P$. acnes (MICs $\leq 0.5 \mu \mathrm{g} / \mathrm{mL}$ ) for the majority of the isolates $(62 / 66 ; 94 \%)$ except three strains with reduced susceptibilities (MIC $>1 \mu \mathrm{g} / \mathrm{mL}$ ) (same strains that were resistant to ciprofloxacin) and one strain with MIC $>2 \mu \mathrm{g} / \mathrm{mL}$. $\mathrm{MIC}_{50}$ and $\mathrm{MIC}_{90}$ values for nadifloxacin $(0.25$ and $1 \mu \mathrm{g} / \mathrm{mL}$, respectively) were twofold lower than those of ciprofloxacin $(0.5$ and $2 \mu \mathrm{g} / \mathrm{mL}$, respectively). As no breakpoint values have been proposed by both CLSI and EUCAST for nadifloxacin, their resistance values could not be determined. Tetracycline showed similar resistance when interpreted by EUCAST and CLSI (9.2\%); no resistance was observed with minocycline when interpreted using CLSI guidelines. $\mathrm{MIC}_{50}$ and $\mathrm{MIC}_{90}$ $(0.125$ and $0.25 \mu \mathrm{g} / \mathrm{mL}$, respectively) of minocycline were also two- to threefold lower than those of tetracycline $(0.38$ and $1 \mu \mathrm{g} / \mathrm{mL}$, respectively).

Multidrug resistance (resistance to three or more classes of drugs) was observed in $9 / 66(13.63 \%)$ of the strains.

Table 4. Minimum inhibitory concentration (MIC) range and percentage of resistance of $P$. acnes isolated from countries across the world.

\begin{tabular}{|c|c|c|c|c|c|c|c|c|c|c|c|c|c|}
\hline \multirow{3}{*}{$\begin{array}{l}\text { Country, year } \\
\text { (no. of isolates) }\end{array}$} & \multirow{3}{*}{$\begin{array}{c}\text { Ref } \\
\text { guidelines }\end{array}$} & \multicolumn{12}{|c|}{$\operatorname{MIC}(\mu \mathrm{g} / \mathrm{mL})$} \\
\hline & & \multicolumn{2}{|c|}{ Erythromycin } & \multicolumn{2}{|c|}{ Clindamycin } & \multicolumn{2}{|c|}{ Tetracycline } & \multicolumn{2}{|c|}{ Minocycline } & \multicolumn{2}{|c|}{ Ciprofloxacin } & \multicolumn{2}{|c|}{ Nadifloxacin } \\
\hline & & Range & $\begin{array}{l}\% \\
\text { R }\end{array}$ & Range & $\begin{array}{l}\% \\
\text { R }\end{array}$ & Range & $\begin{array}{l}\% \\
\text { R }\end{array}$ & Range & $\begin{array}{l}\% \\
\mathrm{R}\end{array}$ & Range & $\begin{array}{l}\% \\
\text { R }\end{array}$ & Range & $\begin{array}{l}\% \\
\text { R }\end{array}$ \\
\hline $\begin{array}{c}\text { Japan, } 2014 \\
(\mathrm{n}=69)\end{array}$ & CLSI & $0.06-256$ & 23.2 & $0.06-256$ & 18.8 & - & 4.3 & $0.06-8$ & 0 & $0.25-32$ & 4.3 & $0.25-16$ & - \\
\hline $\begin{array}{l}\text { Colombia, } 2013 \\
\quad(\mathrm{n}=100)\end{array}$ & CLSI & - & 35 & - & 15 & - & 8 & - & 1 & - & - & - & - \\
\hline $\begin{array}{l}\text { Chile, } 2013 \\
(\mathrm{n}=80)\end{array}$ & CLSI & $0.125-8$ & 12.5 & $0.125-8$ & 7.5 & $0.25-2$ & 0 & - & - & - & - & - & - \\
\hline $\begin{array}{l}\text { Japan, 2006-07 } \\
\quad(\mathrm{n}=50)\end{array}$ & CLSI & $0.063-256$ & 10.4 & $0.063-256$ & 8.3 & - & - & $0.125-0.5$ & 0 & $0.5-2$ & 0 & $0.125-1$ & - \\
\hline $\begin{array}{c}\text { Japan, } 2008 \\
(\mathrm{n}=43)\end{array}$ & CLSI & $0.063-256$ & 20.9 & $0.063 \mathrm{v} 256$ & 18.9 & - & - & $0.25-16$ & 2.3 & $0.125-8$ & 0 & $0.063-4$ & - \\
\hline $\begin{array}{l}\text { Mexico, } 2010 \\
\quad(\mathrm{n}=49)\end{array}$ & CLSI & $0.03-256$ & 46 & $0.03-256$ & 36 & $0.5-256$ & 14 & $0.125-8$ & 0 & $0.125-16$ & 4 & - & - \\
\hline $\begin{array}{c}\text { Japan, } 2008 \\
(\mathrm{n}=48)\end{array}$ & CLSI & $0.063-256$ & 10.4 & $0.031-256$ & 8.3 & $0.5-4$ & 4 & $0.125-4$ & 0 & $0.5-2$ & 0 & $0.125-1$ & - \\
\hline $\begin{array}{l}\text { Chile, 2006 } \\
\quad(\mathrm{n}=53)\end{array}$ & CLSI & $0.03-32$ & 3.8 & $0.03-32$ & 1.9 & $0.03-8$ & 1.9 & $0.03-1$ & 0 & - & - & $0.03-0.12$ & - \\
\hline $\begin{array}{c}\text { Korea, } 2011 \\
(\mathrm{n}=31)\end{array}$ & EUCAST & $\begin{array}{c}0.016- \\
0.125\end{array}$ & 0 & $0.016-0.25$ & 3.2 & $0.094-0.38$ & 0 & $0.023-0.5$ & 0 & - & - & - & - \\
\hline $\begin{array}{l}\text { Hong Kong, } 2011 \\
\qquad(\mathrm{n}=86)\end{array}$ & EUCAST & $0.03-128$ & 20.9 & $0.06-12$ & 53.5 & $0.5-32$ & 16.3 & $0.12-8$ & 16.3 & - & - & - & - \\
\hline $\begin{array}{l}\text { Europe, USA, Japan, } \\
\text { Australia, } 2001(\mathrm{n}= \\
73)\end{array}$ & $\begin{array}{c}\text { Not } \\
\text { Specified }\end{array}$ & $0.03 v 512$ & - & $0.03-64$ & - & $0.125-64$ & - & $0.06-16$ & - & - & - & $0.06-0.25$ & - \\
\hline Current study, India & EUCAST & $0.03-512$ & 7.6 & $0.047-4$ & 10.6 & $0.06-64$ & 9.2 & $0.06-4$ & - & $0.06-64$ & - & $0.06-8$ & - \\
\hline$(\mathrm{n}=66)$ & CLSI & - & 6.1 & - & 0 & - & 9.2 & - & 0 & - & 3 & - & - \\
\hline
\end{tabular}




\section{Discussion}

Cutaneous Propionibacterium has been implicated in acne, although their role in inflammation is still poorly understood. There is widespread resistance in $P$. acnes due to overuse of topical and systemic antibiotics for treatment of acne vulgaris [3,8-16], as shown in Table 4. Various studies have used different interpretative criteria to estimate the resistance among $P$. acne strains to different anti-acne drugs. There is a paucity of data on antibiotic resistance among these isolates in the literature; also, no standard interpretative criterion is available for estimating the resistance among anti-acne drugs in $P$. acnes. Normally, drug susceptibility is not requisitioned, owing to the slow growth of the bacteria and the cost and complexity of testing methods. However, it is important to get resistance information so that correct therapeutic decisions can be made, particularly in resistant cases not responding to routine therapy. At the same time, if facilities that are equipped to perform anaerobic culture are available, the samples should be sent there to get the exact sensitivity pattern for the particular patient, because based on the findings of the study, a fair amount of resistance was observed in the causative organisms.

Our results confirm that $P$. acnes $(66 \%)$ and $S$. aureus $(65 \%)$ predominated the bacterial flora in acne vulgaris patients. This is in contrast to a study done in France by Dreno et al., where among 16 different organisms isolated from acne patients, $S$. epidermidis $(95 \%)$ and $P$. acnes $(90 \%)$ were predominant, followed by $S$. capitis $(47.5 \%)$, Micrococcus $(47.5 \%)$, and $P$. granulosum (32.5\%) [17]. Another study done in Iran by Zandi et al. showed a predominance of $P$. acnes (57\%), followed by S. epidermidis (32\%) and S. aureus (5\%) [18]. This difference in microbial profile in our study could be explained by the variations in geographical location, host factors, and antibiotic usage, as has been described previously.

In the present study, it was observed that resistance among $P$. acnes to anti-acne drugs was lower than that among $S$. aureus. The resistance among $S$. aureus was two- to sevenfold higher than $P$. acnes, with $S$. aureus versus $P$. acnes for: penicillin $(70.2 \%$ versus $6.1 \%)$, ciprofloxacin $(17.9 \%$ versus $3 \%)$, erythromycin $(59 \%$ versus $7.6 \%$ ), clindamycin (39.7\% versus $10.6 \%)$, and tetracycline ( $25 \%$ versus $9.2 \%)$. These findings stress that anti-acne antibiotics continue to maintain activity against $P$. acnes. Lower resistance may be due to the fact that the majority of patients do not undergo treatment of acne in India.
Previously, researchers have used either EUCAST or CLSI guidelines to analyze the resistance profile of $P$. acnes. In present study, resistance rates of erythromycin and clindamycin were higher when analyzed according to EUCAST guidelines $(7.6 \%$ and $10.6 \%$, respectively), as compared to CLSI ( $6 \%$ and $0 \%$, respectively). Tetracycline resistance was observed in $9.2 \%$ of isolates, irrespective of the interpretative criteria used. MIC breakpoints for interpretation are lower in EUCAST guidelines than in CLSI guidelines. From a clinical and epidemiological point of view, EUCAST guidelines are better for analyzing the resistance data than are CLSI guidelines. CLSI guidelines have been used by researchers for drugs where EUCAST data is not available.

In the present study, it was observed that the highest number of isolates (38) showed minimum MIC values of $0.03 \mu \mathrm{g} / \mathrm{mL}$ to penicillin, followed by erythromycin and clindamycin. The MIC range of penicillin was $0.03-0.06 \mu \mathrm{g} / \mathrm{mL}$, although only four strains had MIC $>32 \mu \mathrm{g} / \mathrm{mL}$. Penicillin is not a very good anti-acne antibiotic; however, as it is not available in topical preparations, and has various adverse effects, namely penicillin allergy and anaphylaxis. Among topical antibiotics, erythromycin $(0.03-512 \mu \mathrm{g} / \mathrm{mL})$ and clindamycin $(0.047-4 \mu \mathrm{g} / \mathrm{mL})$ showed very low resistance.

$\mathrm{MIC}_{50}$ and $\mathrm{MIC}_{90}$ values of nadifloxacin $(0.25$ and $1 \mu \mathrm{g} / \mathrm{mL}$ ) were found to be twofold lower than those of ciprofloxacin $(0.5$ and $2 \mu \mathrm{g} / \mathrm{mL}$; thus, nadifloxacin emerged as a better drug for management of acne patients. $\mathrm{MIC}_{50}$ and $\mathrm{MIC}_{90}$ of minocycline $(0.125$ and $0.5 \mu \mathrm{g} / \mathrm{mL}$ ) was also found to be two- to threefold lower than those of tetracycline $(0.38$ and $1 \mu \mathrm{g} / \mathrm{mL})$. Our findings are in sync with studies across the world showing no resistance to $P$. acnes against minocycline.

We searched for relevant studies indexed in the PubMed, Medline, and Google databases for articles with words "Propionibacterium" and "Propionibacterium acnes India". Based on available literature and to the best of our knowledge, this is the first study from India focusing on the bacteriology of acne vulgaris and $P$. acnes resistance.

\section{Conclusions}

Antibiotic resistance in acne vulgaris has gradually risen over the years, making it difficult to treat these patients. This is corroborated by evidence of reduced clinical response to antibiotic therapy, potential increase in pathogenicity of $P$. acnes, and transfer of resistance to more pathogenic organisms. Effective strategies to combat antibiotic resistance in acne are 
required and include judicious and limited duration of antibiotic usage and the use of topical retinoids in lieu of antibiotics.

\section{References}

1. Hanna S, Sharma J, Klotz J (2003) Acne vulgaris: More than skin deep. Dermatol Online J 9: 8.

2. Leyden JJ (1995) New understandings of the pathogenesis of acne. J Am Acad Dermatol 32: 15-25.

3. Ross JI, Snelling AM, Eady EA, Cove JH, Cunliffe WJ, Leyden JJ, Collignon P, Dréno B, Reynaud A, Fluhr J, Oshima S (2001) Phenotypic and genotypic characterization of antibiotic-resistant Propionibacterium acnes isolated from acne patients attending dermatology clinics in Europe, the USA, Japan and Australia. Br J Dermatol 144: 339-346.

4. Witkowski JA, Parish LC (2004) The assessment of acne: An evaluation of grading and lesion counting in the measurement of acne. Clin Dermatol 22: 394-397.

5. Miles RS, Amyes SGB (1996) Laboratory control of antimicrobial therapy. In Collee JG, Fraser AG, Marmion BP, Simmons A, editors. Mackie and McCartney Practical Medical Microbiology, 14th edition. Edinburgh: Churchill Livingstone, Elsevier. 131-150.

6. Clinical and Laboratory Standards Institute (CLSI) (2011) Performance standards for antimicrobial susceptibility testing; twenty first informational supplement. CLSI document M100S2. Wayne, PA: CLSI.

7. European Committee on Antimicrobial Susceptibility Testing (2011) Breakpoint tables for interpretation of MICs and zone diameters, version 1.3, January 5, 2011. Basel: EUCAST.

8. Nakase K, Nakaminami H, Takenaka Y, Hayashi N, Kawashima M, Noguchi N (2014) Relationship between the severity of acne vulgaris and antimicrobial resistance of bacteria isolated from acne lesions in a hospital in Japan. J Med Microbiol 63: 721-728.

9. Mendoza N, Hernandez PO, Tyring SK, Haitz KA, Motta A (2013) Antimicrobial susceptibility of Propionibacterium acnes isolates from acne patients in Colombia. Int J Dermatol 52: 688-692.

10. Schafer F, Fich F, Lam M, Gárate C, Wozniak A, Garcia P (2013) Antimicrobial susceptibility and genetic characteristics of Propionibacterium acnes isolated from patients with acne. Int J Dermatol 53: 418-425.
11. Nakase K, Nakaminami H, Noguchi N, Nishijima S, Sasatsu M (2012) First report of high levels of clindamycin- resistant Propionibacterium acnes carrying erm (X) in Japanese patients with acne vulgaris. J Dermatol: 794-796.

12. Gonzalez R, Welsh O, Ocampo J, Robles RMH, Cabrera LV, Delaney ML, Gomez M (2010) In vitro antimicrobial susceptibility of Propionibacterium acnes isolated from acne patients in northern Mexico. Int J Dermatol 49: 1003-1007.

13. Ishida N, Nakaminami H, Noguchi N, Kurokawa I, Nishijima S, Sasatsu M (2008) Antimicrobial susceptibilities of Propionibacterium acnes isolated from patients with acne vulgaris. Microbiol Immunol 52: 621-624.

14. Gubelin W, Martinez MA, Molina MT, Zapate S, Valenzuela ME (2006) Antimicrobial susceptibility of strains of Propionibacterium acnes isolated from inflammatory acne. Rev Latinoam Microbio 148: 14-16.

15. Song M, Seo SH, Ko HC, Oh CK, Kwon KS, Chang CL, Kim MB (2011) Antibiotic susceptibility of Propionibacterium acnes isolated from acne vulgaris in Korea. J Dermatol 38: 667-673.

16. Luk NM, Hui M, Lee HC, Fu LH, Liu ZH, Lam LY, Eastel M, Chan YK, Tang LS, Cheng TS, Siu FY, Ng SC, Lai YK, Ho KM (2013) Antibiotic resistant Propionibacterium acnes among acne patients in a regional skin centre in Hong Kong. $\mathrm{J}$ Eur Acad Dermatol Venereol 27: 31-36.

17. Dreno B, Reynaud A, Moyse D, Habert H, Richet H (2001) Erythromycin- resistance of cutaneous bacterial flora in acne. Eur J Dermatol 11: 549-553.

18. Zandi S, Vares B, Abdollahi H (2011) Determination of microbial agents of acne vulgaris and Propionibacterium acnesantibiotic resistance in patients referred to dermatology clinics in Kerman, Iran. Jundishapur J Microbiol 4: 17-22.

\section{Corresponding author}

Dr. Rajni Gaind

Department of Microbiology, VMMC \& Safdarjang Hospital

Room no- 508, New Delhi

110029, India

Phone: 09810528344

Email: rgaind5@hotmail.com

Conflict of interests: No conflict of interests is declared. 